\title{
Analisa Pemilihan Sales Terbaik di PT. Enseval Putera Megatreding Tbk, Pematangsiantar dengan metode Profil Matching
}

\author{
Suharyadi', Saifullah ${ }^{2}$, Eka Irawan ${ }^{3}$, Riski Sundari ${ }^{4}$ \\ STIKOM Tunas Bangsa Pematangsiantar \\ Jln. Jend Sudirman Blok A No.1-3 Pematangsiantar, Indonesia \\ suharrrr98@gmail.com
}

\begin{abstract}
Abstract-Sales is the ability of a sales person to sell, which includes the process of selling that comes from the first step to the execution of a sale. So the understanding of sales person or salesmen here is an individual who offers a product in a sales process. In this case sometimes the leaders are confused in determining the best sales at PT ENSEVAL PUTERA MEGATRADING Tbk, Pematang Siantar. This study uses Profile Matching method. This report discusses the selection of the best SALES in PT ENSEVAL PUTERA MEGATRADING Tbk, Pematang Siantar Then calculates consistency using the Profile Matching method. If the consistent value is produced consistently, it can be used as a reference to rank the best sales at PT ENSEVAL PUTERA MEGATRADING Tbk, Pematang Siantar. For the results of all tests can be generated that it is easier to determine the best sales, and become input to the management in lifting the best sales to become permanent employees.
\end{abstract}

Keywords: Sales, Decision Support System, Profile Matching, PT. Enseval Putera Megatrading

Abstrak- Abstrak-Sales adalah kecakapan seorang sales dalam menjual yang meliputi proses dalam penjualan yang di mualai dari langkah pertama sampai dengan terlaksananya suatu penjualan. Jadi pengertian sales person atau salesmen di sini adalah individu yang menawarkan suatu produk dalam suatu proses penjualan. Dalam hal ini terkadang pimpinan bingung dalam mentukan sales terbaik di PT ENSEVAL PUTERA MEGATRADING Tbk, Pematang Siantar. Penelitian ini mengunakan metode Profile Matching. Laporan ini membahas tentang pemilihan SALES terbaik di PT ENSEVAL PUTERA MEGATRADING Tbk, Pematang Siantar Kemudian menghitung konsistensi menggunakan metode Profile Matching. Jika nilai konsisten dihasilkan konsisten, dapat dijadikan acuan untuk memberikan peringkat dari sales yang terbaik di PT ENSEVAL PUTERA MEGATRADING Tbk, Pematang Siantar. Untuk hasil dari seluruh pengujian dapat dihasilkan bahwa lebih mudah dalam menentukan sales terbaik, dan menjadi masukan terhadap pihak menajemen dalam mengangkat sales terbaik menjadi karyawan tetap.

Kata kunci: Sales, SPK, Profile Matching, PT. Enseval Putera Megatrading

\section{PENDAHULUAN}

Sales adalah seorang laki-laki atau perempuan yang direkrut oleh perusahaan untuk mempromosikan produk atau barang yang langsung berhubungan dengan usaha pemasaran produk (KBBI/Kamus Besar Bahasa Indonesia). Mengambil keputusan dalam pemilihan Sales dihadapkan pada permasalahan yang cukup kompleks, mereka dituntut untuk mempertimbangkan sejumlah faktor, seperti kualitas pemasaran, pelayanan dan model. Untuk meningkatkan kualitas Sales, tentu perlu dukungan dari perusahaan. Segala bentuk dukungan sudah semestinya 
diperlukan dalam hal menganalisa Sales yang memiliki potensi baik. Melihat dari peningkatan para Sales yang setiap tahunnya meningkat, perusahaan harus mengerti kebutuhan para Sales tersebut supaya tetap datang pada tepat waktu dan menjalankan tugas-tugas yang di berikan oleh perusahan tersebut. Sumber data ini dikumpulkan berdasarkan data jumlah Sales yang dihasilkan oleh PT. ENSEVAL PUTERA MEGATRADING Tbk, dan merupakan perusahaan multinasional yang mendistribusikan berbagai macam produk. PT. ENSEVAL PUTERA MEGATRRADING Tbk, yang berpusat di JAKARTA. Perusahaan ini tercatat pada tahun 1994.Sistem pendukung keputusan merupakan sistem Informasi interaktif yang menyediakan informasi, pemodelan, informasi interaktif yang menyediakan informasi, pemodelan, dan pemanipulasian data yang digunakan untuk membantu pengambilan keputusan pada situasi pemodelan, dan pemanipulasian data yang digunakan untuk membantu pengambilan keputusan pada situasi yang semiterstruktur dan tidak terstruktur dimana untuk membantu pengambilan keputusan pada situasi yang semi-terstruktur dan tidak terstruktur [1].

Berdasarkan latar belakang tersebut maka perusahaan perlu mengambil sebuah keputusan dalam pemilihan Sales terbaik, yang mana pemilihan sales terbaik tersebut diharapkan akan meningkatkan kinerja sales serta pemasaran dan penjualan perusahaan. Permasalahan dalam pemilihan sales terbaik tersebut dapat diatasi menggunakan Sistem Pendukung Keputusan (Decision Support System). Dalam hal ini penulis mengambil sebuah metode yaitu Profile Matching. Metode ini penulis pilih karena Metode Profile Matching merupakan suatu proses yang sanagat penting dalam manajemen Sumber Daya Manusia (SDM) dimana terlebih dahulu ditentukan kompetensi (kemampuan) yang diperlukan oleh suatu jabatan. Kompetensi kemampuan tersebut haruslah dapat dipenuhi oleh sales atau calon yang akan dinilai kinerjanya. Untuk itu penulis mengambil judul "ANALISA PEMILIHAN SALES TERBAIK DI PT. ENSEVAL PUTERA MEGATRADING Tbk, MENGUNAKAN METODE PROFILE MATCHING". Diharapkan analisa ini dapat dijadikan kontribusi untuk perusahaan dalam hal peningkatkatan kinerja yang ada di tempat perusahaan, dukungan pelatihan peningkatan layanan dan kinerja serta dukungan sosialisasi perusahaan agar kinerja Sales akan semakin meningkat dimasa yang akan datang.

\section{METODOLOGI PENELITIAN}

Metode penelitian menguraikan cara ilmiah untuk mengumpulkan dan menganalisa data, lokasi dan waktu dalam pengumpulan data dengan tujuan dan kegunaan tertentu.

a. Metode Pengumpulan Data

Pengumpulan data merupakan proses pengadaan data primer, untuk kebutuhan suatu penelitian. Adapun teknik pengumpulan data dalam penelitian ini yaitu:

1. Penelitian kepustakaan (Library Research) yaitu memanfaatkan perputakaan sebagai sarana dalam mengumpulkan data, dengan mempelajari buku-buku sebagai bahan referensi. Hal ini dilakuakan dengan membaca tulisan berupa buku dan jurnal yang berkaitan dengan kasus yang diangkat oleh penulis.

2. Penelitian Lapangan (Field Work Research) yaitu penelitian yang dilakukan 
secara langsung dilapangan dengan menggunakan beberapa teknik sebagai berikut:

a) Observasi metode pengumpulan data dengan cara mengadakan pengamatan langsung di PT. ENSEVAL PUTERA MEGATRADING Tbk. Terhadap berbagai kegiatan yang ada .

b) Wawancara dilakukan dengan proses pengumpulan data atau informasi melalui tatap muka antara pihak penanya (interview ) dengan pihak yang ditanya atau penjawab ( interview).

b. Analisis Data, dalam melakukan sebuah penelitian salah satu komponen yang paling penting adalah data penelitian, dimana data tersebut yang nantinya akan diolah untuk mengasilkan sesuatu yang bermanfaat.

c. Analisa Permasalahan, penulis dapat menyimpulkan bahwa permasalahan yang menjadi dasar dilakukannya penelitian ini adalah bagaimana menentukan Sales terbaik di PT. ENSEVAL PUTERA MEGATRADING Tbk.

d. Metode Profile Matching adalah sebuah mekanisme pengambilan keputusan dengan mengasumsikan bahwa terdapat variable predicator yang ideal yang harus dimiliki, bukannya tingkat minimal yang harus dipenuhi atau dilewati dalam proses Metode Profile Matching Modelling secara garis besar merupakan proses membandingkan antara nilai data actual dari suatu profile yang akan dinilai dengan nilai profil yang diharapkan, sehingga dapat diketahui perbedaan kompetensinya (disebut juga gap)[2].

e. Perancangan Flowchart

Flowchat adalah penggambaran secara grafik dalam bentuk diagram alir dari suatu algoritma dalam suatu program yang menyatakan arah alur program dalam menyelesaikan suatu masalah. Berikut adalah flowchart cara kerja Profile Matching :

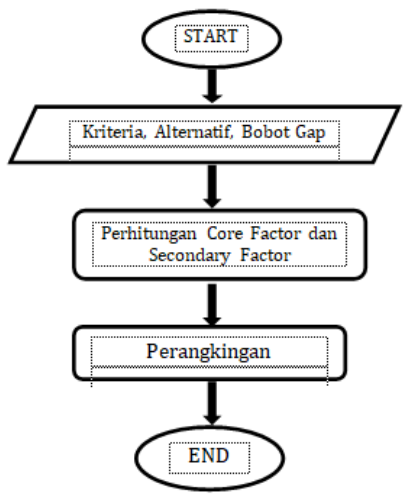

Gambar 1. Flowchart Metode Profile Matching

f. Perhitungan Manual Profile Matching

Pada tahap ini proses perhitungan manual dengan menggunakan rumus Metode Profile Matching. Berikut langkah-langkah penyelesaian yang dilakukan penulis dalam perengkingkan jumlah sales.

1. Data yang akan di perengkingkan 
Tabel 1. Data sales PT. ENSEVAL PUTERA MEGATRADING Tbk.

\begin{tabular}{|l|l|}
\hline NO & NAMA SALES / Alternatif \\
\hline 1. & Yogi (A1) \\
\hline 2. & Zulham (A2) \\
\hline 3. & Mulyadi (A3) \\
\hline 4. & Rudiman (A4) \\
\hline 5. & Jefri Bule (A5) \\
\hline 6. & Ebanzer Hasibuan (A6) \\
\hline 7. & Amad Jais (A7) \\
\hline 8. & Eko (A8) \\
\hline 9. & Putra (A9) \\
\hline 10. & Adi Tirta (A10) \\
\hline 11. & Marjoni (A11) \\
\hline 12. & Lintona (A12) \\
\hline 13. & Karmala (A13) \\
\hline 14. & Heri (A14) \\
\hline 15. & Ali Imran (A15) \\
\hline 16. & Ferryal (A16) \\
\hline 17. & Bambang (A17) \\
\hline 18. & Faisal Halif (A18) \\
\hline 19. & Goldfriston(A19) \\
\hline 20. & Sendi Halim(A20) \\
\hline
\end{tabular}

Metode Profile Matching merupakan salah satu metode yang sederhana dalam sistem pendukung keputusan dengan membandingkan GAP antara nilai Alternatif dan Kriteria. Ada beberapa hal yang diketahui tentang Analisis GAP, salah satu diantaranya adalah tabel nilai bobot GAP. Selain itu analysis GAP ini juga harus memahammi konsep skala prioritas, karena di dalam pembuatan bobot dengan range 0-5 berdasarkan prioritas setiap kriteria. Berikut ini adalah bobot nilai GAP pada Metode Profile Matching yaitu sebagai berikut:

Tabel 2. Keterangan Bobot Nilai GAP

\begin{tabular}{|l|l|l|l|}
\hline NO & Selisih & Bobot Nilai & Keterangan \\
\hline 1 & 0 & 5 & Tidak ada selisih kompentensi sesuai dengan di butuhkan \\
\hline 2 & 1 & 4,5 & Kompentensi individu kelebihan 1 tingkat/level \\
\hline 3 & -1 & 4 & Kompentensi individu kekurangan 1 tingkat/level \\
\hline 4 & 2 & 3,5 & Kompentensi individu kelebihan 2 tingkat/level \\
\hline 5 & -2 & 3 & Kompentensi individu kekurangan 2 tingkat/level \\
\hline 6 & 3 & 2,5 & Kompentensi individu kelebihan 3 tingkat/level \\
\hline 7 & -3 & 2 & Kompentensi individu kekurangan 2 tingkat/level \\
\hline 8 & 4 & 1,5 & Kompentensi individu kelebihan 4 tingkat/level \\
\hline 9 & -4 & 1 & Kompentensi individu kekurangan 4 tingkat/level \\
\hline
\end{tabular}


Tabel 3. Sampel Data Kriteria

\begin{tabular}{|c|c|c|c|c|c|}
\hline No & Nama Kreteria & Presentase & $\begin{array}{l}\text { Nilai Bobot } \\
\text { Profile } \\
\text { Pencapaian }\end{array}$ & Tipe Target & $\begin{array}{c}\text { Nilai Tipe } \\
\text { Target }\end{array}$ \\
\hline \multirow[t]{4}{*}{1} & Sikap Kerja & \multirow[t]{4}{*}{$45 \%$} & & & \\
\hline & -Tanggung Jawab & & 5 & Core & \multirow[t]{2}{*}{60} \\
\hline & -Kejujuran & & 3 & Core & \\
\hline & -Displin & & 2 & Secondary & 40 \\
\hline \multirow[t]{4}{*}{2.} & $\begin{array}{l}\text { Hasil Perstasi } \\
\text { Kerja }\end{array}$ & \multirow[t]{4}{*}{$25 \%$} & & & \\
\hline & -Kecakapan & & 4 & Core & 60 \\
\hline & -Keterampilan & & 3 & Secondary & \multirow[t]{2}{*}{40} \\
\hline & -Pengalaman & & 3 & Secondary & \\
\hline \multirow[t]{3}{*}{3.} & Kesehatan & \multirow[t]{3}{*}{$20 \%$} & & & \\
\hline & $\begin{array}{l}\text {-Memiliki } \\
\text { Riwayat } \\
\text { Penyakit }\end{array}$ & & 2 & Secondary & 40 \\
\hline & $\begin{array}{l}\text {-Tidak Memiliki } \\
\text { Riwayat } \\
\text { Penyakit }\end{array}$ & & 5 & Core & 60 \\
\hline \multirow[t]{3}{*}{4} & Perilaku & \multirow[t]{3}{*}{$10 \%$} & & & \\
\hline & -Kepatuan & & 5 & Core & 60 \\
\hline & -Kesungguan & & 3 & Secondary & 40 \\
\hline
\end{tabular}

Berdasarkan data di atas, berikut ini adalah data asumsi dari nilai bobot alternatif yaitu sebagai berikut.

Tabel 4. Nilai Amsumsi Bobot Profile Matching

\begin{tabular}{|c|c|c|}
\hline \multicolumn{3}{|c|}{ Nilai Asumsi Bobot Profile Matching } \\
\hline No & Keterangan Bobot & Nilai Bobot \\
\hline 1 & Sangat Baik & 5 \\
\hline 2 & Baik & 4 \\
\hline 3 & Cukup & 3 \\
\hline 4 & Kurang & 2 \\
\hline 5 & Sangat Kurang & 1 \\
\hline
\end{tabular}

Langkah I: Menormalisasi Data berdasarkan nilai bobot Profile Matching yaitu :

Tabel 5. Nilai Normalisasi Bobot

\begin{tabular}{|c|c|c|c|c|c|c|c|c|c|c|c|}
\hline No & $\begin{array}{c}\text { Nama } \\
\text { Alternatif }\end{array}$ & $\begin{array}{c}\text { Sub } \\
\text { C1.1 }\end{array}$ & $\begin{array}{c}\text { Sub } \\
\text { C1.2 }\end{array}$ & $\begin{array}{c}\text { Sub } \\
\text { C1.3 }\end{array}$ & $\begin{array}{c}\text { Sub } \\
\text { C2.1 }\end{array}$ & $\begin{array}{c}\text { Sub } \\
\text { C2.2 }\end{array}$ & $\begin{array}{c}\text { Sub } \\
\text { C2.3 }\end{array}$ & $\begin{array}{c}\text { Sub } \\
\text { C3.1 }\end{array}$ & $\begin{array}{c}\text { Sub } \\
\text { C3.2 }\end{array}$ & $\begin{array}{c}\text { Sub } \\
\text { C4.1 }\end{array}$ & $\begin{array}{c}\text { Sub } \\
\text { C4.2 }\end{array}$ \\
\hline 1. & A1 & 4 & 4 & 5 & 4 & 4 & 5 & 3 & 4 & 4 & 4 \\
\hline 2. & A2 & 5 & 4 & 3 & 5 & 4 & 4 & 2 & 5 & 5 & 4 \\
\hline 3. & A3 & 5 & 4 & 5 & 5 & 5 & 4 & 3 & 4 & 5 & 5 \\
\hline 4. & A4 & 5 & 4 & 4 & 4 & 5 & 5 & 1 & 4 & 4 & 3 \\
\hline 5. & A5 & 5 & 5 & 5 & 4 & 4 & 5 & 3 & 4 & 4 & 5 \\
\hline 6. & A6 & 5 & 4 & 4 & 5 & 5 & 5 & 2 & 5 & 4 & 4 \\
\hline 7. & A7 & 5 & 4 & 5 & 4 & 5 & 5 & 2 & 4 & 4 & 5 \\
\hline 8. & A8 & 5 & 4 & 4 & 5 & 5 & 4 & 2 & 4 & 4 & 5 \\
\hline 9. & A9 & 4 & 4 & 4 & 5 & 5 & 4 & 1 & 4 & 4 & 4 \\
\hline
\end{tabular}




\begin{tabular}{|c|c|c|c|c|c|c|c|c|c|c|c|}
\hline No & $\begin{array}{c}\text { Nama } \\
\text { Alternatif }\end{array}$ & $\begin{array}{c}\text { Sub } \\
\text { C1.1 }\end{array}$ & $\begin{array}{c}\text { Sub } \\
\mathbf{C 1 . 2}\end{array}$ & $\begin{array}{c}\text { Sub } \\
\text { C1.3 }\end{array}$ & $\begin{array}{c}\text { Sub } \\
\text { C2.1 }\end{array}$ & $\begin{array}{c}\text { Sub } \\
\text { C2.2 }\end{array}$ & $\begin{array}{c}\text { Sub } \\
\text { C2.3 }\end{array}$ & $\begin{array}{c}\text { Sub } \\
\text { C3.1 }\end{array}$ & $\begin{array}{c}\text { Sub } \\
\text { C3.2 }\end{array}$ & $\begin{array}{c}\text { Sub } \\
\text { C4.1 }\end{array}$ & $\begin{array}{c}\text { Sub } \\
\text { C4.2 }\end{array}$ \\
\hline 10. & A10 & 5 & 5 & 4 & 5 & 4 & 3 & 4 & 3 & 4 & 4 \\
\hline 11. & $\mathrm{~A} 11$ & 5 & 4 & 5 & 4 & 4 & 5 & 4 & 3 & 4 & 4 \\
\hline 12. & $\mathrm{~A} 12$ & 5 & 5 & 5 & 4 & 5 & 4 & 2 & 4 & 4 & 3 \\
\hline 13. & $\mathrm{~A} 13$ & 4 & 5 & 4 & 5 & 4 & 5 & 4 & 2 & 4 & 5 \\
\hline 14. & $\mathrm{~A} 14$ & 4 & 4 & 5 & 4 & 5 & 4 & 2 & 4 & 4 & 4 \\
\hline 15. & $\mathrm{~A} 15$ & 5 & 4 & 5 & 4 & 4 & 5 & 4 & 2 & 5 & 3 \\
\hline 16. & $\mathrm{~A} 16$ & 5 & 5 & 4 & 5 & 4 & 3 & 4 & 2 & 2 & 3 \\
\hline 17. & $\mathrm{~A} 17$ & 5 & 4 & 5 & 4 & 5 & 4 & 2 & 4 & 4 & 4 \\
\hline 18. & $\mathrm{~A} 18$ & 5 & 4 & 5 & 5 & 5 & 5 & 4 & 3 & 5 & 4 \\
\hline 19. & $\mathrm{~A} 19$ & 5 & 4 & 5 & 4 & 5 & 4 & 3 & 4 & 5 & 5 \\
\hline 20. & $\mathrm{~A} 20$ & 5 & 4 & 4 & 5 & 4 & 4 & 5 & 3 & 5 & 5 \\
\hline
\end{tabular}

Langkah II: Menghitung Nilai Maping GAP yang bersumber dari analisis GAP

Tabel 6. Mapping GAP

\begin{tabular}{|c|c|c|c|c|c|c|c|c|c|c|c|}
\hline No & $\begin{array}{c}\text { Nama } \\
\text { Alternatif }\end{array}$ & $\begin{array}{l}\text { GAP } \\
\text { C1.1 }\end{array}$ & $\begin{array}{l}\text { GAP } \\
\text { C1.2 }\end{array}$ & $\begin{array}{l}\text { GAP } \\
\text { C1.3 }\end{array}$ & $\begin{array}{l}\text { GAP } \\
\text { C2.1 }\end{array}$ & $\begin{array}{l}\text { GAP } \\
\text { C2.2 }\end{array}$ & $\begin{array}{l}\text { GAP } \\
\text { C3.3 }\end{array}$ & $\begin{array}{l}\text { GAP } \\
\text { C3.1 }\end{array}$ & $\begin{array}{l}\text { GAP } \\
\text { C3.2 }\end{array}$ & $\begin{array}{l}\text { GAP } \\
\text { C4.1 }\end{array}$ & $\begin{array}{l}\text { GAP } \\
\text { C4.2 }\end{array}$ \\
\hline 1. & $\mathrm{~A} 1$ & 4 & 4,5 & 2,5 & 5 & 4,5 & 3,5 & 4,5 & 4 & 4 & 4,5 \\
\hline 2. & A2 & 5 & 4,5 & 4,5 & 4,5 & 4,5 & 4,5 & 5 & 5 & 5 & 4,5 \\
\hline 3. & A3 & 5 & 4,5 & 2,5 & 4,5 & 3,5 & 4,5 & 4,5 & 4 & 5 & 3,5 \\
\hline 4. & A4 & 5 & 4,5 & 3,5 & 5 & 3,5 & 3,5 & 4 & 4 & 4 & 5 \\
\hline 5. & A5 & 5 & 3,5 & 2,5 & 5 & 4,5 & 3,5 & 4,5 & 4 & 4 & 3,5 \\
\hline 6. & $\mathrm{~A} 6$ & 5 & 4,5 & 3,5 & 4,5 & 3,5 & 3,5 & 5 & 5 & 4 & 4,5 \\
\hline 7. & A7 & 5 & 4,5 & 2,5 & 5 & 3,5 & 3,5 & 5 & 4 & 4 & 3,5 \\
\hline 8. & A8 & 5 & 4,5 & 3,5 & 4,5 & 3,5 & 4,5 & 5 & 4 & 4 & 3,5 \\
\hline 9. & A9 & 4 & 4,5 & 3,5 & 4,5 & 3,5 & 4,5 & 4 & 4 & 4 & 4,5 \\
\hline 10. & A10 & 5 & 3,5 & 3,5 & 4,5 & 4,5 & 5 & 3,5 & 3 & 4 & 4,5 \\
\hline 11. & A11 & 5 & 4,5 & 2,5 & 5 & 4,5 & 3,5 & 3,5 & 3 & 4 & 4,5 \\
\hline 12. & A12 & 5 & 3,5 & 2,5 & 5 & 3,5 & 4,5 & 5 & 4 & 4 & 5 \\
\hline 13. & A13 & 4 & 3,5 & 3,5 & 4,5 & 4,5 & 3,5 & 3,5 & 2 & 4 & 3,5 \\
\hline 14. & A14 & 4 & 4,5 & 2,5 & 5 & 3,5 & 4,5 & 5 & 4 & 4 & 4,5 \\
\hline 15. & A15 & 5 & 4,5 & 2,5 & 5 & 4,5 & 3,5 & 3,5 & 2 & 5 & 5 \\
\hline 16. & A16 & 5 & 3,5 & 3,5 & 4,5 & 4,5 & 5 & 3,5 & 2 & 2 & 5 \\
\hline 17. & A17 & 5 & 4,5 & 2,5 & 5 & 3,5 & 4,5 & 5 & 4 & 4 & 4,5 \\
\hline 18. & A18 & 5 & 4,5 & 2,5 & 4,5 & 3,5 & 3,5 & 3,5 & 3 & 5 & 4,5 \\
\hline 19. & A19 & 5 & 4,5 & 2,5 & 5 & 3,5 & 4,5 & 4,5 & 4 & 5 & 3,5 \\
\hline 20. & A20 & 5 & 4,5 & 3,5 & 4,5 & 4,5 & 4,5 & 2,5 & 3 & 5 & 3,5 \\
\hline
\end{tabular}

Langkah 3: Menghitung Nilai Rata-rata Core Factor dan Nilai rata Secondary Factor yaitu sebagai berikut:

$$
N C F=\frac{\sum N C}{\sum C I}
$$

Keterangan:

NCF : Nilai rata-rata core factor

NC : Jumlah total nilai core factor

IC : Jumlah item core factor 
$N S F=\frac{\sum N S}{\sum I S}$

Keterangan:

NSF : Nilai rata-rata Secondary factor

NS : Jumlah total nilai Secondary factor

IS : Jumlah item Secondary factor

Cara menghitung untuk mendapatkan nilai core factor dan sencondary factor untuk kriteria 1 Alternatif 1 :

NCF $1=(4+4,5) / 2=4,25$

NSF $1=2,5 / 1=2,5$

Nilai Core Factor dan Sencondary Factor Untuk Kriteria 2 Alternatif 1:

NCF $1=5 / 1=5$

NSF $1=(4,5+3,5) / 2=4$

Berdasarkan hasil perhitungan dari nilai core factor dan secondary factor, selanjutnya menghitung nilai total dari kriteria dan core factor dan secondary factor yaitu sebagai berikut:

Nilai dari semua Core Factor dan Sendarary Factor Keriteria 1 Alternatif 1: $(60 / 100 * 4,25)+(40 / 100 * 2,5)=3,55$

Nilai dari semua Core Factor dan Sendarary Factor Keriteria 2 Alternatif 1: $(60 / 100 * 5)+(40 / 100 * 4)=4,6$

Langkah 4: Melakukan Prengkingan.

Berdasarkan Data Nilai NCF dan NSF, maka berikut ini adalah perangkingan dari Metode Profile Matching (anlysis gap) yaitu:

Alternatif $1:(45 / 100 * 3,55)+(25 / 100 * 4,6)+(20 / 100 * 4,2)+(10 / 100 * 4,2)$

$$
=4,008
$$

Alternatif $2:(45 / 100 * 4,65)+(25 / 100 * 4,5)+(20 / 100 * 5)+(10 / 100 * 4,8)$

$$
=4,698
$$

Tabel 7. Perangkingan Profile Matching

\begin{tabular}{|c|c|c|c|}
\hline NO & Nama Alternatif & Nilai Akhir & Keterangan \\
\hline 1. & A1 & 4,008 & Rangking13 \\
\hline 2. & A2 & 4,698 & Rangking 1 \\
\hline 3. & A3 & 4,088 & Rangking 8 \\
\hline 4. & A4 & 4,253 & Rangking 3 \\
\hline 5. & A5 & 3,968 & Rangking 15 \\
\hline 6. & A6 & 4,358 & Rangking 2 \\
\hline 7. & A7 & 4,093 & Rangking 7 \\
\hline 8. & A8 & 4,248 & Rangking 4 \\
\hline 9. & A9 & 4,073 & Rangking 9 \\
\hline 10. & A10 & 3,988 & Rangking 14 \\
\hline
\end{tabular}




\begin{tabular}{|c|c|c|c|}
\hline 11. & A11 & 3,943 & Rangking 16 \\
\hline 12. & A12 & 4,068 & Rangking 10 \\
\hline 13. & A13 & 3,618 & Rangking 20 \\
\hline 14 & A14 & 4,048 & Rangking 11 \\
\hline 15. & A15 & 3,903 & Rangking 17 \\
\hline 16. & A16 & 3,768 & Rangking 19 \\
\hline 17. & A17 & 4,183 & Rangking 5 \\
\hline 18. & A18 & 3,878 & Rangking 18 \\
\hline 19. & A19 & 4,163 & Rangking 6 \\
\hline 20. & A20 & 4,038 & Rangking 12 \\
\hline
\end{tabular}

Maka dari itu dapat disimpulkan dari hasil perhitungan ini yang mendapatkan Rangking 1 (satu) adalah (Alternatif 2), dan mendapat Rengking 2 (dua) adalah (Alternatif 6), mendapat Rengking 3 (tiga) adalah (Alternatif 4).

\section{HASIL DAN PEMBAHASAN}

Pada bab ini penulis akan menguraikan hasil penelitian yang telah dilakaukan sebelum. Berdasarkan metodologi penelitian yang telah dilakukan sebelumnya, penulis mengusulkan sebuah aplikasi yang dapat digunakan oleh PT. ENSEVAL PUTERA MEGATRADING Tbk untuk mengatasi permasalahan yang dihadapi oleh pihak perusahaan, khususnya dalam melakukan pendataan dan atau melakukan perengkingan jumlah sales yang ada di perusahaan dengan manfaatkan metode Profile Mathcing. Berikut tampilan aplikasi sistem informasi data sales PT. ENSEVAL PUTERA MEGATRADING Tbk, Pematangsianatar.yang ingin diususlkan penulis.

a. Halaman Login Database

Halaman Login Database merupakan halaman yang tampil pertama sekali ketika pengguna sistem mengakses sistem informasi perusahaan. Berikut gambar tampilaan halaman login database:

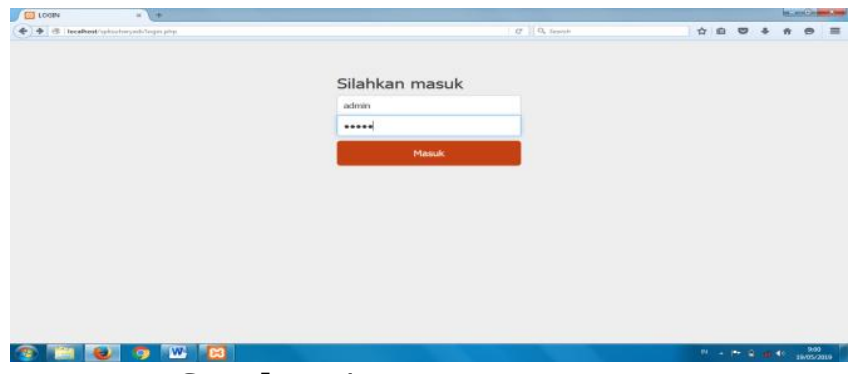

Gambar 1. Form Login

b. Tampilan Grafik Hasil Rengking

From ini ditunjukan Tampilan yang Garafik Hasil Rengkingan dibuat oleh sitem, Tampilan nilai berbentuk Garafik Hasil akhir dapat dilihat pada gambar 4.31 dibawah ini: 


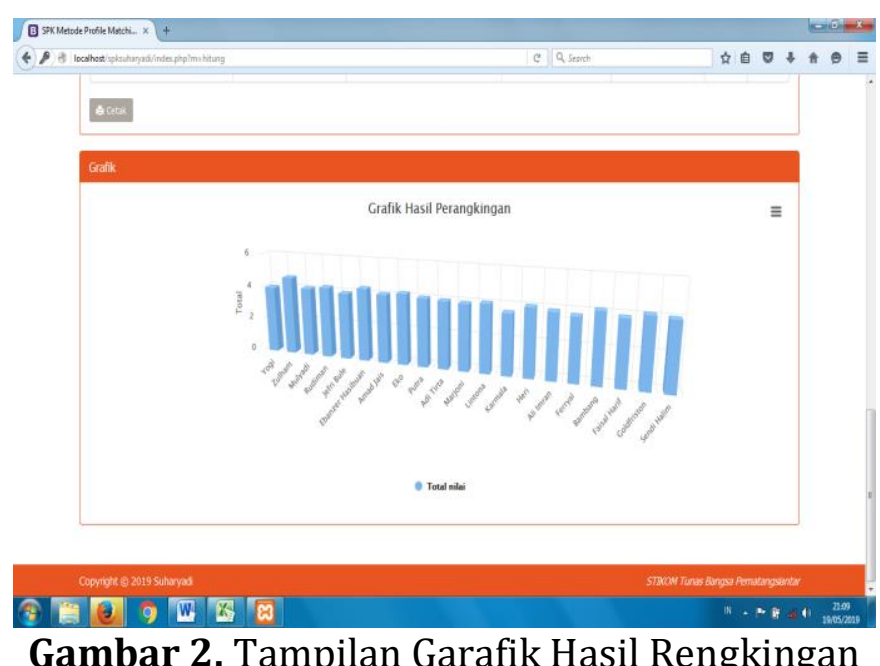

Setelah rancangan sistem dilkaukan uji sistem sebalum dilaksanakan implementasi sistem untuk melihat apakah hasil program telah sesuai atau tidak.

\section{KESIMPULAN}

Sistem Pendukung Keputusan Pemilihan Sales Terbaik di PT. ENSEVAL PUTERA MEGATRADING Tbk, Pematangsiantar.

Dengan Metode Profile Matching Beberapa Kesimpulan lain, Penerapan Algoritma Profile Matching dalam menentukan sales terbaik di PT. ENSEVAL PUTERA MEGATRADING Tbk, Pematangsiantar dapat disimpulkan pemilihan sales terbaik menggunakan Sistem Pendukung Keputusan mempunyai unjuk kerja yang lebih baik. Sumber data yang digunakan dalam penelitian ini berasal dari PT. ENSEVAL PUTERA MEGATRADING Tbk, Pematangsiantar dengan hasil A2. Dalam menetukan kriteria pemilihan Sales tebaik sudah ditetapkan oleh pihak perusahaan

\section{DAFTAR PUSTAKA}

[1] E. Satria, N. Atina, M. E. Simbolon, and A. P. Windarto, "SPK: ALGORITMA MULTIATTRIBUTE UTILITY THEORY ( MAUT ) PADADESTINASI TUJUAN WISATA LOKAL DI KOTA SIDAMANIK," vol. 3, no. 2, pp. 168-172, 2018.

[2] A. Setiawan, Sutardi, Tajidun, LM, 2017, and J. T. Informatika, "SPK Penilaian Dan Pemberian Bonus Salesman Pada Matakar Kendari Menggunakan Profile Matching," semanTIK, vol. 3, no. 1, pp. 199-208, 2017

[3] I. Parlina, A. P. Windarto, A. Wanto, and M. R. Lubis, "Memanfaatkan Algoritma K-Means Dalam Menentukan Pegawai yang Layak Mengikuti Asessment Center," CESS (Journal Comput. Eng. Syst. Sci., vol. 3, no. 1, pp. 87-93, 2018.

[4] A. P. Windarto, "Implementation of Data Mining on Rice Imports by Major Country of Origin Using Algorithm Using K-Means Clustering Method," Int. J. Artif. Intell. Res., vol. 1, no. 2, pp. 2633, 2017.

[5] Sudirman, A. P. Windarto, and A. Wanto, "Data mining tools | rapidminer : K-means method on clustering of rice crops by province as efforts to stabilize food crops in Indonesia," in IOP Conference Series, 2018, pp. 1-8. 